\title{
A Abertura da Privacidade e o Sigilo das Informações sobre o HIV/Aids das Mulheres Atendidas pelo Programa Saúde da Família no Município de São Paulo, Brasil
}

The Opening of Privacy and the Secrecy of HIV/Aids Information concerning Women Assisted by the Family Health Program in the City of São Paulo, Brazil

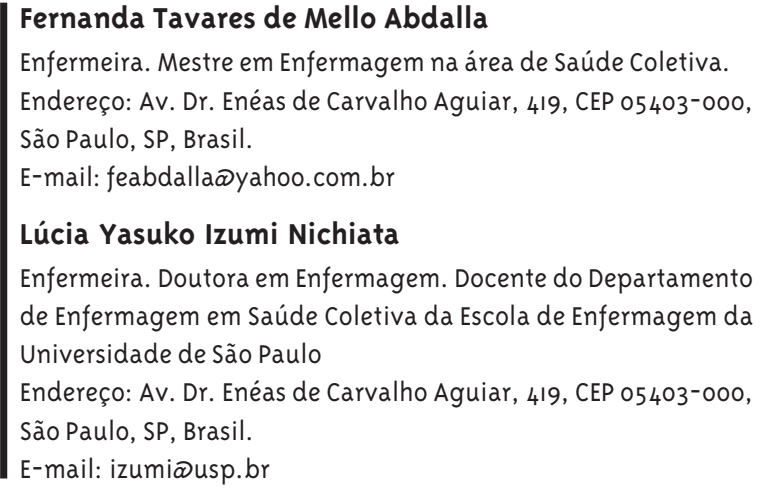

\section{Resumo}

A epidemia da Aids que acometia inicialmente homens, adultos com alta escolaridade e práticas homossexuais, passou atingir mais os jovens, grupos sociais de maior exclusão social, pessoas com práticas heterossexuais e mulheres. A doença, envolta em preconceito que pode levar a discriminação, preocupa as mulheres quanto ao "segredo" da infecção. Este estudo teve como objetivo discutir situações que envolvem questões de privacidade e sigilo das informações nas experiências de assistência do PSF às mulheres portadoras do HIV. É um estudo qualitativo que utilizou metodologias de grupo focal com agentes comunitários de saúde (ACS) e entrevistas semi-estruturadas com enfermeiros, médicos e auxiliares de enfermagem, feito numa Unidade Básica de Saúde que opera com PSF no município de São Paulo. Os depoimentos foram analisados segundo Bardin e organizados nos temas: a) a revelação do diagnóstico de HIV para a usuária; b) acolhimento e vínculo na abertura da privacidade; c) a revelação do diagnóstico de HIV aos membros da equipe de PSF; e d) discussão em equipe e o sigilo das informações. Verificou-se que os profissionais do PSF conhecem o diagnóstico pela própria usuária, familiares, vizinhos, ACS ou outro membro da equipe e profissionais de saúde dos serviços de referência, além do prontuário e resultados de exames. A mulher revela seu diagnóstico quando há confiança e vínculo na relação usuária-profissional. Os profissionais buscam assegurar o sigilo do HIV. A abertura da privacidade da informação possibilita discussão das necessidades de 
saúde da usuária e o planejamento das ações pelo PSF. Palavras-chave: HIV; Aids; Privacidade; Comunicação sigilosa; Saúde da Família.

\section{Abstract}

In the beginning, Aids was predominantly seen in highly educated adult males with homosexual practices. Then, it reached a much younger group, with less access to information, heterosexuals and also women. Those infected with Aids are often worried about discrimination, which makes them keep it secret. The objective of this study was to discuss privacy and confidentiality of information related to women infected with HIV, who were assisted by Family Health Program (FHP) teams. It is a qualitative study that used the focal groups methodology with communitybased health agents and semi-structured interviews with nurses, technicians, and doctors. It was conducted at a Basic Health Unit that operates using an FHP model in São Paulo. Accounts were analyzed according to Bardin and grouped into different categories: a) Revealing HIV diagnosis to FHP users; b) Welcoming and using bonding experiences when talking about the subject; c) Revealing HIV diagnosis to members of the FHP team; d) Team discussion and confidentiality of information. We found out that FHP professionals learn about the diagnosis through the patients themselves, their families, health agents and other healthcare professionals, and of course, through official test results. The women patients feel comfortable to talk about their HIV diagnosis when there is trust in the healthcare professional/user relationship. Professionals always try to ensure confidentiality of information regarding the diagnosis. This information enables professionals to talk about the users' health conditions and helps FHP team members set up a plan of action.

Keywords: HIV; Aids; Privacy; Confidential Communication; Family Health.

\section{Introdução}

No início da década de 1980, a humanidade encontrou o grande desafio de enfrentar a pandemia da Aids, doença causada pelo vírus da imunodeficiência adquirida e que hoje ocupa lugar de destaque entre os principais problemas de saúde no mundo. Ao descrever a trajetória da Aids por meio do número absoluto de casos, observa-se que, nos vinte e seis primeiros anos da epidemia, de 1980 a 30 de julho de 2006, o Brasil notificou 433067 casos (Brasil, 2006).

É conhecido o impacto da epidemia nas mulheres brasileiras. Os dados mostram redução da proporção de homens e mulheres, que passou de 30/1 em 1987, a 7/1 em 1990 e para 3/1 em 1996, e no aumento no número de casos notificados entre as mulheres, observado no incremento de $71 \%$ entre 1980 e 2000 , cerca de nove vezes mais do que o observado entre os homens. Até novembro de 200o, do total de 196016 casos de Aids notificados no Brasil, um quarto eram mulheres (Brasil, 200o).

No processo saúde-doença, na condição da infecção do HIV, existem particularidades específicas da mulher que a diferem do homem, como os fatores biológicos e sociais, que favorecem a infecção pelo vírus e o desenvolvimento da doença. Entre as particularidades destacam-se as diferenças anatômicas, a maior concentração do vírus no sêmen do que na mucosa vaginal, as inflamações e irritações bem como a vulnerabilidade para as doenças sexualmente transmissíveis, a desigualdade social, as questões de gênero, a falta de percepção de risco, principalmente em mulheres envolvidas em relacionamentos estáveis (Villela, 1996). Além disso, após o diagnóstico da infecção, as mulheres enfrentam dificuldades das mais variadas formas, desde aquelas relacionadas diretamente à infecção e ao adoecimento, ao tratamento e aos cuidados diários, até aquelas referidas ao campo afetivorelacional. Segundo analisa Tunala (2002), estas últimas são as principais fontes cotidianas de estresse indicadas pelas mulheres portadoras do vírus, derivadas, muitas vezes, do estigma associado ao HIV, gerando sentimentos de medo, solidão e abandono.

Esses sentimentos acabam, muitas vezes, suscitando a preocupação com o "segredo" da infecção. Segundo analisa Galvão (2004), "muitas vezes é auto-imposta pelo medo que o portador ou doente tem de, ao tornar 
conhecido seu diagnóstico, ficar sujeito a preconceitos e estigmatização". Não entrar em contato com a revelação do seu diagnóstico, muitas vezes, é uma forma de evitar o sofrimento. Não relatar sua doença é mais uma maneira de não se identificar (Pereira, 2001). Por outro lado, quando a mulher conta sobre seu diagnóstico e recebe apoio, há abertura da privacidade aos familiares e aos profissionais de saúde. E quando não têm apoio, estas sofrem rejeição na família e demoram a voltar a ter confiança nas pessoas (Ferreira, 2007).

Segundo afirma Tunala (2002), é necessário que os serviços incorporem intervenções que promovam a saúde das pessoas acometidas pelo HIV e, entre outras coisas, incluam ações que desenvolvam habilidades de busca e recepção de apoio social (amigos, parentes, instituições, serviços da comunidade e outras), bem como capacidade de fazer negociações nas diversas relações. Para Ferreira (2007), é necessário que os serviços de saúde que operam com o modelo de Programa Saúde da Família (PSF) promovam ações relacionadas à discussão de questões pertinentes ao viver com HIV/Aids, a fim de diminuir os preconceitos existentes na comunidade.

No âmbito da epidemia de HIV/Aids, as ações são amplas e complexas para toda população em geral e, principalmente, para os grupos específicos. O PSF trabalha com a estratégia privilegiada de intensificar as ações de promoção da saúde e prevenção do HIV, garantindo melhor qualidade de vida aos indivíduos portadores do HIV/Aids e familiares (São Paulo, 2003).

"Uma boa assistência pode melhorar, em muito, a qualidade de vida das pessoas com HIV", segundo Silva e colaboradores (2005). As ações visam, particularmente, fortalecer vínculos familiares e sociais na assistência e convivência com as pessoas acometidas pelo HIV/Aids. Além disso, devem ser desenvolvidas estratégias a fim de promover o aumento da adesão ao tratamento, às normas de biossegurança e prevenção as DST/Aids pelos pacientes, familiares e cuidadores. Para que o PSF possa planejar e realizar as ações voltadas às mulheres acometidas pelo HIV é necessário que as equipes tenham conhecimento da informação sobre o diagnóstico de HIV.

As discussões sobre os conflitos éticos que os profissionais de saúde do PSF encontram no seu cotidiano sobre a manutenção das informações e da privacidade dos usuários, especialmente na questão do HIV/
Aids, são objetos do presente estudo e podem servir como subsídios para a reflexão das práticas do PSF e, conseqüentemente, para a melhoria da qualidade da assistência em saúde.

Este estudo teve como objetivo discutir as situações que envolvem questões de privacidade e sigilo das informações nas experiências de assistência às mulheres portadoras de HIV/Aids, vivenciadas pelas equipes do Programa Saúde da Família.

\section{Procedimentos Metodológicos}

Com o PSF inserido na realidade social da comunidade é importante a discussão de temas sobre bioética, especificamente no caso da Aids. De acordo com os conceitos de autonomia, a mulher portadora do HIV tem o direito de escolher se a informação sobre seu diagnóstico do HIV deve o não ser revelada e em quais circunstâncias a abertura de sua privacidade pode ocorrer.

O projeto foi aprovado pelo Comitê de Ética da Secretaria Municipal de Saúde de São Paulo e pelo Comitê de Ética da Fundação Zerbini. De acordo com a resolução CNS/MS 196/96, que regulamenta a ética em pesquisa envolvendo seres humanos no Brasil, foi pedido a cada um dos profissionais de saúde que participaram o seu consentimento livre e esclarecido, visando garantir o anonimato dos participantes e assegurar que se sintam protegidos e seguros para abordar as questões relativas às ações de saúde prestadas.

O presente estudo foi desenvolvido na Unidade Básica de Saúde Vila Penteado, localizada no distrito administrativo de Brasilândia, no município de São Paulo. A unidade opera com o modelo assistencial do PSF desde abril de 1998, através da parceria Secretaria Estadual da Saúde de São Paulo, Secretaria Municipal da Saúde e Fundação Zerbini. Possui horário de funcionamento das 7 h às 19 h. A UBS Vila Penteado foi escolhida por ter uma história de luta popular e por ser a UBS com maior número de equipes de PSF da região. Atualmente, de acordo com o Sistema de Informação da Atenção Básica, com dados de março de 2007, existem 24665 pessoas e 6857 famílias cadastradas.

0 atendimento é feito através da territorialização, ou seja, cada equipe atende a população residente no território de sua responsabilidade, e todos os territórios das equipes conformam a área de abrangência da UBS. As equipes atendem por meio do acolhimento, 
que é a demanda espontânea que bate à porta da UBS com queixas pontuais, atendem pelo agendamento de consultas médicas e de enfermagem, nos grupos educativos e nas visitas domiciliares. Os auxiliares de enfermagem, além de participarem das atividades das equipes, também compõem a escala de cobertura de ambulatório que abrange atividades como a coleta de exames, curativo e vacinação. Os sujeitos de pesquisa foram os profissionais de saúde que compõem as sete equipes de PSF da UBS Vila Penteado: médicos, enfermeiras, auxiliares de enfermagem e agentes comunitários de saúde (ACS). Dos sete médicos, cinco foram entrevistados, dois não dispunham de horário para a entrevista, mesmo após várias tentativas. Do total de sete enfermeiras, seis foram entrevistadas e uma estava de licença maternidade. Todas as 14 auxiliares de enfermagem foram entrevistadas.

Os dados foram coletados por meio de uma entrevista individual realizada com médicos, enfermeiras e auxiliares de enfermagem. As entrevistas foram gravadas em fitas cassete e posteriormente transcritas. Junto aos 28 ACS foi utilizada a metodologia do Grupo Focal. Optou-se por tal método no intuito de identificar situações vivenciadas pelos profissionais e estimular as discussões nos grupos.

Trata-se de um estudo qualitativo de natureza exploratória. Os conteúdos das entrevistas individuais e dos Grupos Focais foram organizados pela Análise de Conteúdo de Bardin (1995) e definidos como um conjunto de técnicas de análise das comunicações que permitem descrever, através de procedimentos sistemáticos, os conteúdos das mensagens, que podem ser quantitativas ou não, e a inferência dos conhecimentos relativos à produção destas mensagens, as variáveis inferidas. Dentre as técnicas desse procedimento metodológico, utilizou-se análise temática que "consiste em descobrir os núcleos de sentido que compõem uma comunicação e cuja presença ou freqüência signifiquem alguma coisa para o objetivo analítico escolhido". O método de análise de conteúdo é composto por quatro fases: a pré-análise, a exploração do material, o tratamento dos resultados e a interpretação (Minayo, 2004). Após uma leitura mais aprofundada, definiu-se agrupar os resultados interpretados em quatro conjuntos temáticos: a) a revelação do diagnóstico de HIV para a usuária; b) acolhimento e vínculo na abertura da privacidade; c) a revelação do diag- nóstico de HIV aos membros da equipe de PSF; e d) discussão em equipe e o sigilo das informações.

\section{Resultados}

\section{A revelação do diagnóstico de HIV para a usuária}

A revelação do diagnóstico de HIV para a usuária foi analisada pelas equipes de PSF segundo as situações que fizeram com que o(s) membro(s) da equipe suspeitasse(m) da infecção e indicasse(m) a realização do teste sorológico, e como se deu o momento de revelação. De acordo com as falas dos ACS, médicos, enfermeiras e auxiliares de enfermagem, foram observadas três situações em que o profissional de saúde do PSF solicitou o teste anti-HIV às mulheres.

Na primeira situação, a solicitação do teste foi feita pelo profissional médico e/ou enfermeira na consulta, quando havia suspeita de infecção pelo HIV, aventada pela presença de sintomatologia na história de vida da usuária ou alguma indicação de comportamento de risco. Ao realizar a anamnese, se o profissional de saúde, de um modo geral, percebe indícios de que um usuário encontra-se em situações de risco de infecção pelo HIV, passa a solicitar o teste diagnóstico (Ferraz, 1998). Destaca-se que o que chamou a atenção dos profissionais, além dos sintomas, são os chamados “comportamentos de risco", quais seja a história de uso abusivo de álcool, a falta de adesão ao tratamento de outros agravos, como a hipertensão arterial, a falta de proteção na relação sexual.

A segunda situação de solicitação do teste antiHIV ocorreu quando algum membro da equipe trouxe a preocupação ao médico e/ou enfermeira em relação a um possível diagnóstico. A conformação da equipe do PSF incorpora um novo trabalhador: o ACS. E por ter maior proximidade com o usuário, por habitar o mesmo bairro e, ainda, por adentrar freqüentemente o domicílio das famílias, o ACS é um integrante da equipe de saúde da família que traz contribuição fundamental nas relações com os usuários do sistema público de saúde (Fortes e Spinetti, 2004). Os ACS têm um papel fundamental na questão do HIV/Aids no sentido de reconhecer mais precocemente, nas famílias, possíveis portadores e encaminhar para os cuidados necessários.

A terceira situação em que o pedido de teste antiHIV foi feito deu-se no acompanhamento do pré-natal, 
como rotina. A oferta do teste na gestação é uma das principais ações do Programa de Controle das DST/ Aids. Desde 1999, no Estado de São Paulo, é obrigatório o oferecimento do teste anti-HIV a todas as mulheres grávidas nos serviços de pré-natal. A magnitude da infecção do HIV/Aids e o fenômeno de feminilização da epidemia mostram a importância da solicitação do teste anti-HIV a todas as gestantes.

No presente estudo não foi encontrado nenhum relato sobre situação em que a usuária tenha procurado a equipe para a realização voluntária do teste antiHIV. Isso pode ter ocorrido pela não lembrança por parte dos entrevistados e ACS ou pelo fato de não ter ocorrido situação descrita. Longa (1999) lembra que os motivos mais freqüentes para o comportamento daqueles que não buscam espontaneamente os serviços de saúde para a realização da sorologia para o HIV podem estar relacionados ao medo do diagnóstico ou de sua confirmação, à falta de informações sobre a infecção pelo HIV/Aids e ao desconhecimento da importância de um diagnóstico precoce. Segundo Czeresnia (1997), uma possível discriminação e rejeição social que a usuária poderá sofrer podem fazer com que esta tenha vergonha, caso o seu diagnóstico seja positivo.

O PSF é de extrema importância para garantir um diagnóstico precoce do HIV. O profissional do PSF, ao dialogar com as usuárias e suas famílias sobre as diferentes situações de vulnerabilidade às DST e HIV/ Aids, pode encorajar a procura espontânea pelo teste. A revelação do diagnóstico à usuária é um momento delicado e importante, pois traz angústia, tristeza e medo, tanto para a usuária quanto para o profissional. Apreende-se das falas que, na maioria das situações relatadas, foi o médico da equipe o profissional que revelou o diagnóstico do HIV. Outra situação de revelação do diagnóstico ocorreu num trabalho em parceria do médico e da enfermeira da equipe.

O PSF tem como característica a articulação do trabalho entre os membros da equipe de saúde, construindo-se projetos de intervenção comum. Entre os membros da equipe houve a preocupação com os mitos e medos criados em torno da Aids. E, nesse sentido, procuraram, nas ações desenvolvidas, desmistificar a doença, chamando a atenção para termos que comumente levam à discriminação e ao preconceito. É comentado, em um dos grupos focais, o medo do preconceito que a mulher acha que vai sofrer se a família e a vizinhança souberem do seu diagnóstico de HIV. Na questão do HIV/Aids, segundo Parker e Aggleton (2002), preconceito, estigma e discriminação são assuntos bastante debatidos por causarem impacto na epidemia, especialmente ao dificultarem a prevenção de futuras infecções e as ações de assistência.

Após a revelação do diagnóstico do HIV para a mulher, o médico e a enfermeira entrevistados sentiram que houve a necessidade de acolher a paciente e ganhar a sua confiança, conforme a dinâmica de trabalho da equipe. A confiança que a usuária sente pelo profissional é fundamental na construção do vínculo.

\section{Acolhimento e o vínculo na abertura da privaci- dade da mulher HIV/Aids}

Apreende-se das falas dos membros da equipe do PSF que acolhimento e vínculo são determinantes para que se estabeleça a confiança entre estes e a usuária, précondição para que ocorra a abertura da privacidade das informações.

Nos discursos dos entrevistados e nos grupos focais, foram observadas diferentes definições para acolhimento. Segundo enfermeira e auxiliar de enfermagem, acolhimento possibilita ao usuário "falar sobre o que sente e sobre suas necessidades”. É um espaço que proporciona escuta e auxilia na resolução de eventuais questões que preocupam o usuário. É observado no conteúdo das falas do ACS e da auxiliar de enfermagem que o acolhimento é necessário para detectar as necessidades dos usuários e para exercer as ações de saúde, e, para a sua realização, o profissional deve proporcionar um ambiente propício à escuta. Nas falas dos entrevistados, destaca-se que as relações entre as equipes de PSF e as usuárias, portadoras de HIV/Aids, devem ser acolhedoras.

Para Matumoto (1998), o acolhimento resgata valores de solidariedade, respeito com o outro, estabelecimento de vínculo entre os envolvidos, acesso aos serviços e, conseqüentemente, responsabilizando os profissionais de saúde pelos problemas da população e buscando construir caminhos para solucioná-los. As ações de acolhimento fazem parte do processo de trabalho do PSF e são essenciais para que o vínculo entre o profissional de saúde e o usuário/família seja construído. De fato, observa-se que os profissionais do PSF realizam essas ações e estão dispostos a contribuir para as mudanças em saúde da comunidade. 
Os profissionais entrevistados mostram um envolvimento tanto profissional quanto emocional pelos usuários, especialmente às mulheres portadoras do HIV e às famílias. Dedicam-se nas orientações de auto-cuidado, dialogam sobre prevenção e promoção da saúde, conduzem os grupos educativos e realizam as visitas domiciliárias de forma a contemplar as necessidades de saúde da comunidade.

Segundo os ACS, na construção do vínculo são necessários tempo e paciência. Na fala da auxiliar de enfermagem, a construção do vínculo se faz especialmente nas visitas domiciliares, já que é neste momento que a usuária abre as portas de sua casa para receber o profissional. A confiança e o vínculo, estabelecidos no relacionamento entre o profissional e a usuária, são condições para que haja a abertura da privacidade das informações sobre o diagnóstico de HIV aos membros da equipe de PSF. A confiança pode ser estabelecida ao longo do tempo pelos sujeitos que se relacionam. A confiança pressupõe honestidade, sinceridade nas atitudes e no diálogo, compartilhada pelo usuário e o profissional. Observa-se que quando a usuária confia no seu ACS pode se sentir à vontade para abrir sua privacidade e revelar seu diagnóstico. De fato, a confiança depositada no ACS foi identificada como um dos principais elementos que possibilitam a abertura da privacidade, no sentido da revelação do diagnóstico. Ferreira (2007) comenta que um dos motivos para a decisão de revelar o diagnóstico à equipe está relacionado ao bom atendimento e acolhimento, estando presente a confiança nos profissionais do PSF.

$\mathrm{Na}$ abertura da privacidade é necessário que se estabeleça um acordo de confidencialidade, um pacto. A privacidade e a confidencialidade são princípios complexos que se correlacionam entre si. A privacidade consiste no conjunto de informações sobre uma pessoa, que pode decidir mantê-las sob seu exclusivo controle, ou comunicar, decidindo em que medida e a quem, quando, onde e em que condições o outro poderá acessar as informações. Já a confidencialidade se relaciona na garantia (no sentido de confiança) de que as informações confiadas não serão reveladas sem prévia autorização da pessoa em questão. Ou seja, a privacidade das informações é um direito dos usuários do serviço, ao mesmo tempo em que a confidencialidade é um dever dos profissionais em relação às informações geradas e confiadas no relacionamento pro- fissional-usuário (Massarollo e col., 2006).

Para que o usuário confie no profissional, a auxiliar de enfermagem relata que a confidencialidade das informações é fundamental. É importante que o sigilo das informações seja mantido para que o usuário freqüente o serviço de saúde. Segundo Fortes e Spinetti (2004), que desenvolveram um estudo num momento inicial do PSF, existe, por parte dos ACS, a preocupação em manter o sigilo profissional como princípio ético da privacidade. Cabe a todos os profissionais de saúde estabelecerem condições para que o usuário possa decidir sobre quais informações quer manter em segredo, e quais quer comunicar aos familiares, amigos ou aos profissionais de saúde.

Fortes e Spinetti (2004) discutem que a organização do trabalho no PSF facilita que as informações sejam disseminadas, até mesmo as sigilosas. Segundo os autores, tal fato traz implicações éticas no que diz respeito à privacidade e à autonomia dos usuários (que engloba a intimidade, a vida privada e a honra das pessoas), especialmente no que tange a informações pessoais que possam trazer algum grau de discriminação e/ou estigmatização, em particular no caso de pessoas afetadas pelo HIV/Aids.

Em uma situação, a usuária quis manter o segredo de seu diagnóstico a um dos profissionais da equipe, no caso, uma auxiliar de enfermagem, por ela ser membro de sua família. Após ter sido reforçada pela médica a questão do sigilo das informações, a usuária sentiu-se mais segura para compartilhar seu segredo com esta profissional. A explicação sobre o dever do sigilo, esclarecendo para a usuária as questões sobre privacidade e confidencialidade, reforça a credibilidade nos profissionais (Ferreira, 2007).

Um dos médicos comenta sobre a necessidade de estimular a abertura da privacidade pela mulher portadora do HIV ao parceiro que não sabe sobre o diagnóstico. Este destaca que deve-se procurar convencer a usuária a contar sobre o diagnóstico de soropositividade ao parceiro ou se colocar à disposição no momento de revelação.

Portanto, a partir das ações de acolhimento e da construção do vínculo entre a usuária HIV/Aids e o profissional de saúde, há uma aproximação entre ambos. Assim, se há o estabelecimento da confiança entre eles, pode surgir o momento em que a mulher tenha o desejo de revelar ao profissional seu diagnóstico de HIV. 


\section{A revelação do diagnóstico de HIV aos membros da equipe de PSF}

De acordo com os relatos nos Grupos Focais, nas entrevistas das auxiliares de enfermagem, das enfermeiras e dos médicos, foi a própria usuária portadora do HIV que freqüentemente revelou o seu diagnóstico aos membros da equipe de PSF. Portanto, as usuárias abrem a privacidade de sua informação às equipes. Em relação aos ACS, estes tiveram conhecimento sobre usuárias com diagnóstico de HIV das seguintes fontes: a própria usuária, familiares das usuárias, vizinhos e outros ACS. É o ACS quem possui maior número de fontes vindas da comunidade quando comparado aos demais membros das equipes. Os ACS reforçaram em suas falas que a usuária revelou para outro profissional da equipe, na maioria dos casos não de imediato, aspectos de sua vida privada e sobre ser portadora do HIV. Isso ocorreu somente após ter estabelecido, de alguma forma, um contato mais próximo com algum profissional da equipe e quando se encontrou num momento mais vulnerável de sua vida.

Em 2005, o PSF de Vila Penteado, devido a uma ampliação de suas equipes, readequou sua área de abrangência. Desta forma, algumas famílias que eram assistidas por uma determinada equipe, passaram para outra. Esse foi um momento em que informações das famílias foram compartilhadas entre os profissionais de saúde, inclusive sobre membros portadores do HIV. Observa-se que as informações sobre usuárias com diagnóstico de HIV chegaram a auxiliar de enfermagem por diferentes fontes, no caso sete, sendo ela a profissional que acessou a maior quantidade, tais como serviço de referência, prontuário, resultado de exame, familiar da usuária, própria usuária, ACS e enfermeira. Isso ocorreu porque a auxiliar de enfermagem é um dos membros da equipe que mais oportunidades de contato têm com as famílias e seus membros, através de suas inúmeras atribuições. É o profissional que realiza visitas domiciliárias e procedimentos de enfermagem no domicílio, tais como coleta de exames, curativos, aplicação de vacinas. Além disso, ela participa dos grupos educativos e das reuniões de equipe, responsável, muitas vezes, pelo recebimento dos resultados dos exames laboratoriais e pela assistência na demanda da unidade, realizando ações de imunização, procedimentos técnicos como verificação de pressão arterial e administração de medicação etc.
Comparativamente, as enfermeiras receberam a informação sobre o diagnóstico de HIV de um maior número de fontes que os médicos. As primeiras tiveram como fontes a própria usuária, os familiares, o ACS, o médico e os exames laboratoriais. Já os médicos tiveram como fontes a própria usuária, o ACS, o prontuário e o exame. Não há referência nas falas dos médicos de que a informação tenha chegado diretamente da família para este profissional. O fato de ambos os profissionais, médicos e enfermeiras, realizarem suas atividades, em sua maioria, na própria UBS, pode explicar o menor número de fontes de informação a que eles têm acesso. Destaca-se que a informação sobre o diagnóstico do HIV pode ter sido comentada entre os vizinhos e pela família da usuária. Os vizinhos, que também residem na área de responsabilidade do ACS, acabaram contando a ele sobre usuárias, possivelmente portadoras do HIV. Uma outra forma com que a informação chegou aos membros das equipes foi por meio dos serviços de referência e na leitura do prontuário. Outras fontes de revelação da informação aos membros das equipes foram relatadas quando uma auxiliar de enfermagem viu o resultado de exame laboratorial. Um dos médicos questiona que muitos exames chegam abertos, sendo tal fato possivelmente relacionado à organização dos serviços.

Uma outra forma com que a informação chegou aos membros das equipes foi através dos serviços de referência. Nas ações de prevenção e assistência as DST/ Aids na rede de atenção básica, destaca-se a importância que o PSF vem assumindo, no sentido de ampliar as ações para os grupos vulneráveis à infecção e aqueles que já se encontram infectados. Diante disso, é importante o estabelecimento de mecanismos de comunicação entre os diferentes serviços da Atenção Básica e serviços especializados, desde que sejam garantidos a privacidade e o sigilo sobre a condição do usuário.

Após a revelação do diagnóstico de infecção do HIV aos membros da equipe houve situações em que a informação foi compartilhada no interior da equipe, em momentos de discussões entre os profissionais.

\section{Discussão em equipe e a questão do sigilo das informações}

As auxiliares de enfermagem e as enfermeiras destacam que as discussões em equipe, não só no HIV/Aids 
como em outras questões, são diferenciais na prática do PSF. As discussões promovem envolvimento dos profissionais das equipes com os usuários e suas famílias.

0 médico relatou que é importante discutir os casos de mulheres HIV positivas para que haja a "democratização das idéias”, já que o PSF trabalha com a dinâmica da equipe. Também é comentado pelos ACS que tudo é discutido em equipe porque a dinâmica do trabalho sugere que "deve-se pensar em equipe". As necessidades de saúde identificadas junto às famílias são discutidas no interior da equipe, antes mesmo do conhecimento sobre o diagnóstico de HIV. Vale destacar que muitas situações familiares são de difícil abordagem pelas equipes, necessitando, muitas vezes, de um trabalho de acompanhamento das equipes de Saúde Mental, sendo esta participação um diferencial importante na organização do processo de trabalho deste PSF e no cuidado dos portadores do vírus.

Conforme já se discutiu anteriormente, a partir do conhecimento da informação do diagnóstico de HIV por algum membro da equipe, de um modo geral este compartilha com o restante do grupo. Isso ocorre em vários momentos de discussão, seja no espaço formal de reunião de equipe, seja em outro onde se discute as demandas das famílias. Dessa forma, os casos de mulheres portadoras de HIV acabaram sendo de conhecimento de todos os membros da equipe, segundo se identificou no estudo. Há a preocupação em relação ao sigilo, no sentido de que outras equipes do PSF não conheçam estes casos. Os profissionais relataram manter confidencialmente as informações da usuária. Contudo, é importante que o profissional de saúde estimule a usuária a consentir o compartilhamento da informação sobre seu diagnóstico e a abertura da sua privacidade para os profissionais de PSF. Apreendese das falas que, muitas vezes, ocorre abertura da privacidade e o compartilhamento das informações sobre mulheres HIV/Aids entre os membros da equipe de PSF e equipe de Saúde Mental, sem que tenha ocorrido o consentimento ou autorização prévia da usuária para que isso ocorresse. Entende-se que cabe aos profissionais de saúde discutir previamente com os usuários para que haja o consentimento da abertura da privacidade e compartilhamento das informações com os demais membros da equipe.

Numa outra situação, um dos médicos relata que, após explicar a dinâmica de trabalho do PSF, foi per- guntado à usuária sobre a possibilidade de abertura do seu diagnóstico aos outros membros da equipe. Para Fortes e Spinetti (2004), o PSF caracteriza-se pelo vínculo e pela responsabilidade da equipe em relação às famílias de sua área de abrangência e salientam que é necessário o estabelecimento de contratos de manutenção do sigilo por parte das equipes em relação aos usuários. É importante que o profissional explique aos usuários o processo de trabalho do PSF, as práticas que envolvem as discussões dos casos e os propósitos dessas discussões, incentivando para que o usuário veja a equipe de PSF como uma possibilidade de apoio, não se restringindo a um único membro.

Segundo os ACS, algumas vezes discute-se a manutenção da privacidade com a usuária. Por exemplo, uma mulher solicitou que algumas de suas informações não fossem anotadas no relatório do ACS. Esse exemplo mostrou que a usuária nem sempre quer abrir sua privacidade, não só em relação ao diagnóstico do HIV, mas sobre outras informações que julga serem importantes na sua vida. A abertura da privacidade da informação pela usuária à equipe de PSF está baseada na confiança estabelecida. Segundo a auxiliar de enfermagem, ao abordar o assunto com a usuária sobre a manutenção do sigilo, estabelece-se uma relação de confiança. Almeida e Munoz (1993) ressaltam que a relação usuário-profissional é baseada na confiança mútua.

Em uma fala, o auxiliar de enfermagem refere que manter o sigilo é o mesmo que manter o respeito pelo usuário. Ao manter guardado o segredo do usuário, está, ao mesmo tempo, respeitando as suas decisões.

Um dos médicos comenta sobre a diferença do uso do sigilo, vivenciada num serviço de saúde diferente do modelo de PSF. Nos serviços de saúde em geral, as informações sobre o usuário ficam restritas apenas ao médico; já no PSF é condição do trabalho das equipes o compartilhamento e a discussão sobre as informações e os fatos referentes aos usuários.

Há situações em que não há o compartilhamento da informação sobre o diagnóstico de mulheres acometidas pelo HIV/Aids com todos os membros da equipe. Os membros ponderam sobre a necessidade de abrir para toda a equipe o conhecimento sobre algum caso de HIV, discutem que deve envolver somente aqueles que diretamente podem, de alguma forma, contribuir com as ações de assistência. 
A manutenção da confidencialidade do segredo por todos os elementos da equipe deve ser feita lembrando que são sigilosas não somente as informações reveladas confidencialmente, mas todas aquelas que a equipe de saúde descobre no exercício de sua atividade, mesmo havendo desconhecimento do usuário (Fortes e Spinetti, 2004).

Com freqüência o ACS tem conhecimento sobre o diagnóstico do HIV, mas a usuária não sabe disso. Nas conversas com a usuária, o ACS não deixa transparecer que sabe do diagnóstico, alegando que é uma questão de "ética" não poder falar. Para manter a sua privacidade, a usuária fala apenas dos sintomas da Aids, sem revelar seu diagnóstico; por sua vez, o ACS aborda o assunto de maneira a não identificar sua situação de portadora. Além disso, esse profissional salienta que as usuárias com HIV nunca solicitaram explicitamente da equipe que haja sigilo frente ao diagnóstico, mas mesmo assim refere que o sigilo é mantido.

A preocupação com a preservação da confidencialidade recai particularmente sobre o ACS, por residir na área de abrangência de sua equipe. Dentre suas atribuições, encontra-se "não divulgar informações recebidas durante as visitas domiciliares a quaisquer pessoas que não pertençam à equipe de saúde". Silva e Dalmalso (2002) sugerem que, talvez por esta razão, o próprio agente reconheça como características para trabalhar na função "ser discreto" e não "falar da vida alheia".

A equipe do PSF deve ter o máximo de discrição e discernimento ao escolher o que deve ser revelado e para quem. Deve-se procurar saber junto ao usuário quais são seus desejos quanto à revelação de informações suas para a família e amigos, não cedendo à insistência de quem procura saber algo. Especialmente no caso de HIV/Aids, este é um assunto a ser tratado com a própria usuária. A enfermeira reforça aos ACS e demais membros da equipe a importância de não revelar informações dos usuários para pessoas que não são da equipe e para os familiares. Para Neves (2003), a revelação do diagnóstico de soropositividade não deve ser feita sequer para os familiares, se assim o usuário desejar. Existem casos em que a usuária é resistente em revelar seu diagnóstico para a família, pois quer manter sua privacidade. Nesse caso, o ACS age como se não soubesse do diagnóstico para que a família não perceba e comenta que sofre com isso, o que pode indicar o envolvimento do profissional com a usuária e a família.

Em algumas situações, segundo as falas dos sujeitos de pesquisa, quando a família sabe do diagnóstico pode, de alguma forma, haver apoio. Quando a família sabe do diagnóstico do HIV e existe o apoio, há melhor qualidade do diálogo e da escuta terapêutica e esta participa das ações de saúde planejadas em equipe. Silveira e Carvalho (2002) mostram que a família, peça fundamental no tratamento, ao se propor a cuidar do familiar atingido pelo HIV, enfrenta problemas como as dificuldades em lidar com o aparecimento da sintomatologia. Para que a família possa ajudar é preciso que a equipe de saúde se proponha a ajudá-la nas dificuldades que surgirem ao longo do desenvolvimento da doença. E essa ajuda pode iniciar-se na escuta do familiar/cuidador num trabalho grupal. o familiar mostra-se aliviado ao desabafar seus medos e preocupações e sentir-se apoiado pela equipe de saúde.

Destaca-se que a discussão em equipe é um diferencial no PSF, oportunidade em que há o compartilhamento das necessidades de saúde identificadas e o planejamento conjunto das ações. O compartilhar das informações pela equipe deve ser o mínimo necessário para elaborar ações que propõem satisfazer as necessidades de saúde das famílias e indivíduos. Dessa forma, há o compartilhamento da informação sobre o diagnóstico de HIV/Aids entre os membros da equipe, sendo discutido o seu caráter sigiloso.

\section{Considerações Finais}

As situações que envolvem questões de privacidade e sigilo das informações nas experiências de assistência às mulheres portadoras de HIV/Aids, vivenciadas pelas equipes do PSF, foram analisadas segundo quatro temas: a) a revelação do diagnóstico de HIV para a usuária; b) acolhimento e vínculo na abertura da privacidade; c) a revelação do diagnóstico de HIV aos membros da equipe de PSF; e d) discussão em equipe e o sigilo das informações.

O primeiro tema, a revelação do diagnóstico de HIV para a usuária, refere-se às situações que fizeram com que o(s) membro(s) da equipe suspeitasse(m) da infecção e indicasse(m) a realização do teste sorológico, e como se deu o momento de revelação para a usuária. Os relatos mostraram que a solicitação do 
teste de detecção do vírus partiu do profissional médico ou enfermeira, quando havia sintomatologia da infecção, pela história de vida da usuária e/ou alguma indicação de "comportamento de risco". Em outras situações, os ACS foram aqueles que primeiro suspeitaram de uma possível infecção e depois levaram esta preocupação aos demais profissionais. Dessa forma, os ACS possuem papel fundamental no apoio à detecção precoce de casos na comunidade.

Outras situações de pedido de realização do teste anti-HIV aconteceram nos atendimentos de pré-natal. A detecção precoce de gestantes HIV tem se mostrado como uma das ações que pode reduzir as chances de transmissão da infecção da mãe para o filho e deve ser precedida pelo aconselhamento. Para sua realização há necessidade de capacitação e orientação dos profissionais, para que entendam a importância deste para o estabelecimento de vínculo com a usuária. Considera-se que o aconselhamento para a realização do teste anti-HIV pode ser realizado em outras situações de atendimento que não só de pré-natal, tais como consultas médica ou de enfermagem, coleta de papanicolaou, visitas domiciliares, grupos de planejamento familiar etc. É fundamental que os profissionais não deixem de realizar o aconselhamento em todas as situações para que o usuário sinta-se bem esclarecido e seguro para aceitar (ou não) realizar o teste.

A ausência da procura espontânea pelo teste antiHIV nos relatos pode indicar desde o desconhecimento sobre a possibilidade de realização do teste antiHIV, como a existência do medo de enfrentar um possível diagnóstico e da discriminação que poderão sofrer caso haja a comprovação da infecção. De qualquer maneira, considera-se que os profissionais de saúde do PSF devem abordar temas que envolvem a Aids, como preconceito, estigma e solidariedade, com as famílias e sua comunidade. Os temas devem estar incluídos nas ações já planejadas e desenvolvidas pela equipe de PSF. As equipes podem ainda executar ações que desenvolvam habilidades de busca e recepção de apoio social, fortalecimento de vínculos familiares e sociais na assistência e convivência com as pessoas acometidas pelo HIV/Aids. Considera-se que as equipes de PSF podem assumir o compromisso de buscar estratégias para a redução do preconceito e da discriminação com pessoas portadoras do HIV/Aids.
Na revelação do diagnóstico do HIV à mulher, as situações relatadas mostraram que é interessante quando há parceria do médico com a enfermeira da equipe. 0 trabalho em parceria pode trazer maior segurança à usuária neste momento delicado. Ela pode sentir-se mais à vontade para falar sobre seus medos, suas incertezas, dúvidas e encontrar maior apoio para sua assistência. Além disso, compartilhar da responsabilidade sobre a revelação do diagnóstico entre os profissionais pode trazer segurança e apoio mútuo, favorecer o esclarecimento de dúvidas e discutir condutas a serem tomadas.

Considerando o princípio da autonomia, a mulher portadora do HIV/Aids tendo a capacidade de decidir nas questões que dizem respeito a si própria, como indivíduo, deve decidir se quer contar ou não o seu diagnóstico à equipe de PSF, ou seja, abrir ou não a privacidade desta informação. Ao mesmo tempo, entende-se que, para que haja o planejamento e o desenvolvimento das ações específicas à mulher HIV/Aids e aos membros das famílias sob responsabilidade das equipes, é necessário que haja a abertura de sua privacidade. E isso deve ser estimulado pelos profissionais do PSF. São condições para a abertura da privacidade da informação as ações de acolhimento que auxiliam na construção do vínculo e no estabelecimento da confiança. Porém, mesmo com o estímulo à abertura da privacidade, a mulher tem autonomia para recusar compartilhar informações sobre sua vida com a equipe de PSF.

Nas falas dos sujeitos de pesquisa foi identificado o segundo tema: Acolhimento e vínculo na abertura da privacidade, e nas situações analisadas, de fato, as ações de acolhimento permitem a construção do vínculo e o estabelecimento da confiança na relação entre o profissional, o usuário e as famílias. $\mathrm{O}$ acolhimento deve fazer parte do atendimento dos usuários dos serviços de saúde, especialmente das mulheres portadoras do HIV, para que haja a construção do vínculo e o estabelecimento da confiança na relação entre a equipe de PSF e a mulher HIV/Aids. Com isso, a usuária sente-se segura em abrir sua privacidade para o profissional. As informações que fazem parte da privacidade da mulher podem auxiliar o planejamento das ações pertinentes às necessidades de saúde da usuária, sendo ela co-participante desse planejamento. 
Nas situações descritas pelos membros das equipes, pôde-se apreender que são várias as definições que estes dão ao acolhimento. Entende-se que é necessário discutir nas equipes o sentido dado a acolhimento, as formas de sua expressão, as formas de operacionalizá-lo pelos membros da equipe, mas, mais do que isso, buscar identificar com as usuárias suas necessidades em relação ao acolhimento. 0 vínculo estabelecido com a família é condição para o desenvolvimento das ações no PSF. No entanto, segundo as falas dos sujeitos da pesquisa, não está muito claro o significado do que seja vínculo. Concordam que é necessário tempo e paciência, que as visitas domiciliárias são fundamentais para a sua construção e que há o sentimento de proximidade com as famílias. No entanto, não está clara a existência ou não de limite para o estabelecimento do vínculo. Identificou-se que há o envolvimento dos profissionais nas situações, trazendo muitas vezes sentimentos como sofrimento, gerando desgaste dos profissionais. Essas são questões que devem ser abordadas nas equipes.

No vínculo entre as famílias, seus indivíduos e as equipes de PSF, quando há confiança, a usuária pode abrir a privacidade das informações sobre seu diagnóstico de HIV/Aids. Das falas apreendeu-se que o profissional deve inicialmente discutir com ela o estabelecimento de um acordo, no qual as informações reveladas serão mantidas em segredo entre os profissionais. A garantia da confidencialidade das informações é essencial para a manutenção do relacionamento do profissional com a usuária. Nesse acordo é importante que se discuta com a usuária quais informações podem ser compartilhadas com os membros da equipe e quais vão ser mantidas em sigilo por todos.

Relacionado ao tema a revelação do diagnóstico de HIV aos membros da equipe de PSF, mostrou-se que o ACS é um dos profissionais que mais próximo está das questões que envolvem a privacidade e o sigilo das informações. No entanto, apreendeu-se das falas que, muitas vezes, este se encontra em situações de difícil abordagem, não sabendo muito como proceder, principalmente nos casos em que a usuária não sabe que ele conhece o seu diagnóstico. O estímulo para a abertura da privacidade pode contribuir para uma discussão mais franca, auxiliando na realização das ações. A informação sobre o diagnóstico de membros das famílias chegou por outras fontes que não só pelo exa- me realizado pela própria equipe e pela abertura da privacidade da usuária. Ela foi feita também pelos familiares, amigos e vizinhos. Cabe à equipe discutir o contexto de cada família, o significado dessa informação, as condutas a partir do conhecimento dessa informação. A princípio, se a própria usuária não abriu a privacidade dessa informação para a equipe, devemse buscar estratégias para que ela própria o faça.

Outra forma importante de conhecimento do diagnóstico de HIV de mulheres deu-se pelo serviço de referência da região. Neste aspecto, considera-se importante que haja a comunicação entre estes e os de PSF, desde que sejam tomadas medidas que assegurem a confidencialidade desta informação. Nesse sentido, são necessários também cuidados em relação ao envio de resultados de exames sorológicos e na manipulação dos prontuários.

No tema discussão em equipe e o sigilo das informações destaca-se que a discussão em equipe é um diferencial no PSF, oportunidade em que há o compartilhamento das necessidades de saúde identificadas e o planejamento conjunto das ações. Dessa forma, há o compartilhamento da informação sobre o diagnóstico de HIV/Aids entre os membros da equipe, sendo discutido o seu caráter sigiloso. Conforme já se discutiu, é preciso criar condições para que a usuária autorize o compartilhamento das informações do seu diagnóstico. Nesse momento, é importante que o profissional esclareça sobre o processo de trabalho das equipes de PSF. O fato de ter o profissional ACS como membro da comunidade traz implicações sobre a preservação do sigilo e confidencialidade das informações, conforme se discutiu.

Portanto, no interior das equipes estas são situações que devem ser discutidas, especialmente em relação às formas de abordar as famílias e garantir a manutenção do sigilo, às dificuldades para a construção de vínculos e o estabelecimento de confiança, às formas de acolhimento das necessidades de saúde das famílias etc.

Conclui-se que o PSF pode incluir ações voltadas às mulheres portadoras do HIV/Aids e que a abertura da privacidade pela usuária pode auxiliar na resposta às necessidades de saúde pelas equipes de PSF. As ações de acolhimento no fortalecimento do vínculo e no estabelecimento da confiança são processos fundamentais para que ocorra a abertura da privacidade. Ao 
mesmo tempo, cabe aos profissionais de saúde do PSF desenvolver habilidades e mecanismos que possam garantir a confidencialidade e o sigilo das informações.

\section{Referências}

ALMEIDA, M.; MUNOZ, R. D. Relação médico-paciente e paciente-instituição na Aids: o direito á informação e a confidência, a discriminação e a coerção. Bioética, Brasília, DF, v. 1, n. 1, p. 49-53, 1993.

BARDIN, L. Análise de conteúdo. Lisboa: Ed. 70, 1995. BOLETIM EPIDEMIOLÓGICO Aids. Ministério da Saúde. Brasília, DF: Ministério da Saúde, ano 13, n. 1, 2000

BOLETIM EPIDEMIOLÓGICO Aids/DST. Ministério da Saúde. Brasília, DF, ano 3, n. 1, 1ª à $26^{\text {a }}$ semanas epidemiológicas, jan./jul. 2006.

CZERESNIA, D. Do contágio à transmissão: ciência e cultura na gênese do conhecimento epidemiológico. Rio de Janeiro: Fiocruz, 1997.

FERRAZ, A. F. Aprender a viver de novo a singularidade da experiência de tornar-se portador do HIV e doente com Aids. 1998. Tese - Escola de Enfermagem da Universidade de São Paulo, São Paulo, 1998.

FERREIRA, F. C. As condições que levam as mulheres soropositivas ao HIV/Aids a abrir sua privacidade de suas informações às equipes do Programa Saúde da Família. 2007. Dissertação (Mestrado em Enfermagem em Saúde Coletiva) - Escola de Enfermagem da Universidade de São Paulo, São Paulo, 2007.

FORTES, P. A. C.; SPINETTI, S. R. O agente comunitário de saúde e a privacidade das informações dos usuários. Cadernos de Saúde Pública, Rio de Janeiro, v. 2o, n. 5, p. 1328-1333, 2004.

GALVÃO, M. T. G. et al. Medidas contraceptivas e de proteção da transmissão do HIV por mulheres com HIV/Aids. Revista de Saúde Pública, São Paulo, v. 38, n. 2, p. 194-200, 2004.

LONGA, P. A. R. R. C. A trajetória do portador HIV: da suspeita da infecção à assistência. 1999. Dissertação - Escola de Enfermagem da Universidade de São Paulo, São Paulo, 1999.
MASSAROLLO, M. K. B. et al. Autonomia, privacidade e confidencialidade. In: OGUISSO, T.; ZOBOLI, E. L. C. P. (Org.). Ética e bioética: desafios para a enfermagem e a saúde. São Paulo: Manolle, 2006. p.136-152.

MATUMOTO, S. O. Acolhimento: um estudo sobre seus componentes e sua produção em uma unidade da rede básica de serviços de saúde. 1998.

Dissertação - Escola de Enfermagem da Universidade de São Paulo, Ribeirão Preto, 1998.

MINAYO, M. C. S. O desafio do conhecimento: pesquisa qualitativa em saúde. 8. ed. São Paulo: Hucitec, 2004.

NEVES, F. R. A. O Aconselhamento para a realização da sorologia anti-HIV em gestantes: factibilidade e utopias. 2003. Dissertação - Escola de Enfermagem da Universidade de São Paulo, Ribeirão Preto, 2003.

PARKER, R; AGGLETON, P. HIV and Aids-related stigma and discrimination: a conceptual framework and implications for action. Rio de Janeiro:

Associação Brasileira Interdisciplinar de Aids, 2002.

PEREIRA, M. L. D. A (re)invenção da sexualidade feminina após a infecção do HIV. 2001. Tese - Escola de Enfermagem da Universidade de São Paulo, São Paulo, 2001.

SÃO PAULO (Estado). Secretaria de Estado da Saúde. Coordenação dos Institutos de Pesquisa. Ações de prevenção e assistência as DST/Aids na rede de atenção básica à saúde do estado de São Paulo. São Paulo, 2003.

SILVA, L. M. S. et al. Integralidade em saúde: avaliando a articulação e a co-responsabilidade entre o Programa de Saúde da Família e um serviço de referência em HIV/Aids. Epidemiologia dos Serviços Saúde, Brasília, DF, v. 14, n. 2, p. 97-104, 2005.

SILVA, J. A.; DALMALSO, A. S. W. O agente comunitário de saúde e suas atribuições: os desafios para os processos de formação de recursos em saúde. Interface-Comunicação, Saúde, Eduação, Botucatu, v. 6, n. 10, p. 75-96, 2002.

SILVEIRA, E. A. A.; CARVALHO, A. M. P. Familiares de clientes acometidos pelo HIV/Aids e o atendimento prestado em uma unidade ambulatorial. Revista Latino Americana de Enfermagem, Ribeirão Preto, v. 10, n. 6, p. 813-818, 2002. 
TUNALA, L. G. Fontes cotidianas de estresse em mulheres portadoras do HIV. Revista de Saúde

Publica, São Paulo, v. 36, p. 24-31, 2002. Suplemento 4.

VILLELA, W. Oficinas de sexo mais seguro para

mulheres: abordagens metodológicas e de avaliação.

São Paulo: Nepaids, 1996.

Recebido em: II/05/2007

Reapresentado em: 11/03/2008

Aprovado em:25/03//2008

152 Saúde Soc. São Paulo, v.17, n. 2, p.140-152, 2008 